Research Article

Genetics of Microorganisms

\title{
Role of error-prone DNA polymerases in spontaneous mutagenesis in Caulobacter crescentus
}

\author{
Alexy O. Valencia ${ }^{1}$ (D) , Vânia S. Braz ${ }^{1}$, Magna Magalhães ${ }^{1}$ and Rodrigo S. Galhardo ${ }^{1}$ \\ ${ }^{1}$ Universidade de São Paulo, Instituto de Ciências Biomédicas, Departamento de Microbiologia, São Paulo, \\ SP, Brazil.
}

\begin{abstract}
Spontaneous mutations are important players in evolution. Nevertheless, there is a paucity of information about the mutagenic processes operating in most bacterial species. In this work, we implemented two forward mutational markers for studies in Caulobacter crescentus. We confirmed previous results in which A:T $\rightarrow \mathrm{G}: \mathrm{C}$ transitions are the most prevalent type of spontaneous base substitutions in this organism, although there is considerable deviation from this trend in one of the loci analyzed. We also investigated the role of $\operatorname{din} B$ and imuC, encoding error-prone DNA polymerases, in spontaneous mutagenesis in this GC-rich organism. Both dinB and imuC mutant strains show comparable mutation rates to the parental strain. Nevertheless, both strains show differences in the base substitution patterns, and the dinB mutant strain shows a striking reduction in the number of spontaneous - 1 deletions and an increase in $\mathrm{C}: \mathrm{G} \rightarrow \mathrm{T}: \mathrm{A}$ transitions in both assays.
\end{abstract}

Keywords: DinB, ImuC, DnaE2, spontaneous mutagenesis, Caulobacter crescentus.

Received: September 25, 2018; Accepted:April 4, 2019.

\section{Introduction}

Spontaneous mutations, arising without exposure of cells to external genotoxic agents, arise at a constant rate in all organisms (Drake, 1991; Lynch, 2010). Although most organisms show a bias towards $\mathrm{C}: \mathrm{G} \rightarrow \mathrm{T}: \mathrm{A}$ transitions among spontaneous base substitutions, we have recently found that the bacterium $C$. crescentus shows a different trend, with more A:T $\rightarrow$ G:C substitutions among spontaneous mutations in the rpoB gene (Martins-Pinheiro et al., 2017). Nevertheless, use of rроB as a mutational marker has limitations, such as the relatively small number of amino acid changes leading to the detectable phenotype $\left(\right.$ Rif $\left.^{\mathrm{R}}\right)$ and the lack of detection of insertions and deletions.

Error-prone polymerases are widespread in nature (Ohmori et al., 2001), playing an important role in DNA damage tolerance in bacteria by promoting translesion DNA synthesis (TLS) (Fuchs and Fujii, 2013). As a direct consequence of their TLS activity and their regulation by many cellular stress responses, error-prone polymerases are likely important players in the mutational processes both in growing and non-growing bacterial cells (Galhardo et al., 2007). These enzymes have been extensively studied in Escherichia coli, where the SOS-regulated genes

Send correspondence to Rodrigo S. Galhardo. Universidade de São Paulo, Instituto de Ciências Biomédicas, Departamento de Microbiologia, Butantã, São Paulo, SP, Brazil. E-mail: rgalhard@usp.br. $u m u D C$ and $\operatorname{din} B$ encode the error prone polymerases Pol V and Pol IV respectively.

The role of these enzymes in DNA damage tolerance in $E$. coli is clear. Pol $\mathrm{V}$ is required for damage-induced mutagenesis after cellular exposure to a number of different DNA damaging agents, such as UV light, methyl nitrosoguanidine, and 4-NQO (Kato and Shinoura, 1977; Bagg et al., 1981; Woodgate, 1992). Pol IV is involved in error-free bypass of both alkylation damage (Bjedov et al., 2007) and $\mathrm{N}^{2}$-guanine adducts (Jarosz et al., 2006). Deletion of the $\operatorname{din} B$ gene does not affect the rate of spontaneous mutations (Mckenzie et al., 2003; Kuban et al., 2004), and neither the sequences of the mutations observed in the rроB gene (Wolff et al., 2004). Due to the very tight transcriptional and post-transcriptional control of Pol V activity (Goodman et al., 2016), umuDC genes are assumed to have little effect on spontaneous mutagenesis. On the other hand, both DinB and UmuDC have been implicated in untargeted mutagenesis in SOS-constitutive cells (Caillet-Fauquet and Maenhaut-Michel, 1988; Kim et al., 1997, 2001), and also in stress-induced mutagenesis (Cirz et al., 2005; Petrosino et al., 2009). Additionally, $\operatorname{din} B$ is subject to many layers of regulation in E. coli, being induced by the SOS response (Kenyon and Walker, 1980), upon entry into stationary phase (Layton and Foster, 2003) and by beta-lactam antibiotics (Pérez-Capilla et al., 2005).

C. crescentus bears two genes encoding error-prone polymerases in its genome, $\operatorname{din} B$, and imuC (dnaE2), the 
later one being part of a conserved operon also containing $i m u A$ and $i m u B$. Previous studies have shown that this operon is part of the SOS response both in C. crescentus and in other bacteria where these three genes are induced as part of the SOS response and cooperate in a mutagenesis pathway responsible for Mitomycin $\mathrm{C}$ - and $\mathrm{UV}$-induced mutagenesis (Boshoff et al., 2003; Galhardo et al., 2005; Warner et al., 2010). Nevertheless, constitutive transcription of imuABC in SOS-induced levels does not promote significant increases mutation rates in $C$. crescentus, suggesting a tight control of this mutagenesis pathway in cells experiencing DNA damage (Alves et al., 2017). Furthermore, the same study showed that the activity of ImuABC is RecA-independent, setting it apart from the paradigm of mutagenic DNA polymerase regulation in E. coli. Therefore, imu $A B C$ are thought of as functional substitutes of $u m u D C$ in bacteria lacking these genes, although its properties and regulation show considerable differences.

On the other hand, the physiological role of $\operatorname{din} B$ in $C$. crescentus is still not understood. Differently from $E$. coli, this gene is not part of the SOS regulon (Galhardo et al., 2005; da Rocha et al., 2008), and is not upregulated in response to UV light, hydroxyurea and mitomycin C (Modell et al., 2011).

In an attempt to better understand the physiological role of error-prone polymerases and to obtain a better appraisal of the characteristics of spontaneous mutagenesis in C. crescentus, we implemented two forward mutational assays. With these tools, we investigated the characteristics of spontaneous mutagenesis in $C$. crescentus and analyzed the role of DinB and ImuC in this process. We found that DinB has a major role in the generation of spontaneous deletions in the $C$. crescentus genome.

\section{Materials and Methods}

\section{Bacterial strains and growth conditions}

The bacterial strains and plasmids used in this work are listed in Table 1. C. crescentus strains were grown in PYE or M2 glucose (Ely, 1991), at $30{ }^{\circ} \mathrm{C}$ with constant shaking at $250 \mathrm{rpm}$ for liquid cultures. When needed, the following concentrations of antibiotics were used: ampicillin $200 \mu \mathrm{g} / \mathrm{mL}$ (for selection of $\mathrm{Amp}^{\mathrm{R}}$ mutants in the xylbla assay); tetracycline $4 \mu \mathrm{g} / \mathrm{mL}$ (for selection of $\mathrm{Tet}^{\mathrm{R}}$ mutants in the cltet assay); kanamycin $5 \mu \mathrm{g} / \mathrm{mL}$; nalidixic acid $20 \mu \mathrm{g} / \mathrm{mL}$.

\section{Introduction of the $\mathrm{Cl}$ (Ind) $\lambda \mathrm{pR}$ tet $A$ marker in the $C$. crescentus genome}

The $c I$ (Ind $\left.{ }^{-}\right) \lambda \mathrm{pR}$ tet $A$ cassette, hereafter referred to as cItet marker for simplicity, was originally constructed for use as a forward mutational marker in E. coli (Bjedov et al., 2007). This marker scores mutations in the $c I$ repressor gene, leading to constitutive expression of tet $A$, and therefore, tetracycline resistance. For integration of this marker in the $C$. crescentus chromosome, a 538 bp fragment corresponding to the region between bases 2404103 and

Table 1 - Bacterial strains and plasmids used in this study.

\begin{tabular}{|c|c|c|}
\hline Strain & Relevant Genotype & Source \\
\hline \multicolumn{3}{|l|}{ C. crescentus } \\
\hline NA1000 & Parental strain, C. crescentus $\mathrm{CB} 15$ derivative & Evinger and Agabian, 1977 \\
\hline CS606 & NA1000 $\triangle$ blaA & West et al., 2002 \\
\hline GM40 & NA1000 imuC::Spec ${ }^{\mathrm{R}}$ & Galhardo et al., 2005 \\
\hline GM50 & NA1000 $\operatorname{din} B:: \mathrm{Spec}^{\mathrm{R}}$ & Galhardo et al., 2005 \\
\hline RSG113 & NA1000 $\Delta$ blaA $\Delta x y l X:: b l a A$ & This study \\
\hline RSG124 & NA1000 $\Delta$ blaA $\Delta x y l X::$ blaA $\operatorname{din} B:: \mathrm{Spec}^{\mathrm{R}}$ & This study \\
\hline RSG247 & NA1000 $\Delta$ blaA $\Delta x y l X::$ blaA imuC::Spec ${ }^{\mathrm{R}}$ & This study \\
\hline RSG317 & NA1000 $c I\left(\right.$ Ind $\left.^{-}\right) \lambda$ R tet $A$ & This study \\
\hline RSG318 & $\mathrm{NA} 1000 \mathrm{cI}\left(\mathrm{Ind}^{-}\right) \lambda \mathrm{pR}$ tetA imuC::Spec $\mathrm{R}^{\mathrm{R}}$ & This study \\
\hline RSG319 & $\mathrm{NA} 1000 c I\left(\mathrm{Ind}^{-}\right) \lambda \mathrm{pR}$ tetA $\operatorname{din} B:: \mathrm{Spec}^{\mathrm{R}}$ & This study \\
\hline \multicolumn{3}{|l|}{ E. coli } \\
\hline MG1655, $c I$ marker & MG1655 att $\lambda: c I\left(\right.$ Ind $\left.^{-}\right) \lambda \mathrm{pR}$ tetA $\triangle$ ara:FRT $\Delta m e t R E: F R T$ & Bjedov et al., 2007) \\
\hline \multicolumn{3}{|l|}{ Plasmids } \\
\hline pNPTS138 & pNPTS129 derivative, oriT $s a c B \mathrm{Kan}^{\mathrm{R}}$ & Tsai and Alley, 2001 \\
\hline pNPTxylblaE2 & In frame substitution of $x y l X$ by blaA with flanking regions, cloned in pNPTS138 & This study \\
\hline pMCS7 & Cloning vector, non-replicating in C. crescentus & Thanbichler et al., 2007 \\
\hline pMCSCI & $\begin{array}{l}\text { pMCS } 7 \text { containing the } \text { cItet cassette and } \sim 500 \text { bp of DNA for homologous recombination } \\
\text { in the } C \text {. crescentus chromosome }\end{array}$ & This study \\
\hline
\end{tabular}


2404622 of the NA1000 genome was amplified using primers inter3fwd and inter3rev (Table S1). This fragment served as the homology region for recombination of the final construct on the chromosome. This amplicon was cloned in the pMCS7 integrative vector in the NdeI site, using restriction sites introduced in the primers. The resulting plasmid was digested with $K p n I$ and $S m a$ I to receive the $c I$ cassette. The $c I$ cassette was amplified from the genomic DNA of the MG1655 $c I$ (Ind') $\lambda$ pR tetA E. coli strain using the cItetfowkpn and cItetrevsac primers (Table S1) and cloned in the above construct. The resulting plasmid, pMCSCI $\left(\mathrm{Gent}^{\mathrm{R}}\right)$, was introduced in E. coli $\mathrm{S} 17.1$ by electroporation, and passed to C. crescentus NA1000 via conjugation, resulting in strain RSG317, which yielded spontaneous $\mathrm{Tet}^{\mathrm{R}}$ mutants, unlike the parental strain NA1000. $\operatorname{din} B$ and $i m u C$ derivatives of RSG317 were constructed using $\Phi \mathrm{Cr} 30$ transduction using GM40 and GM50 strains as donors.

\section{Construction of the xylbla marker}

We envisaged a strategy to replace the $x y l X$ gene, which is necessary for the metabolism of xylose but dispensable for growth in rich media (Stephens et al., 2007a), by blaA, conferring resistance to ampicillin (West et al., 2002), to construct a novel marker for mutagenesis studies using a native $C$. crescentus gene. The resulting strain is phenotypically $\mathrm{Amp}^{\mathrm{S}}$ in the absence of xylose, but $\mathrm{Amp}^{\mathrm{R}}$ after mutations (i) inactivating the XylR repressor, and (ii) altering the XylR operator sequences in the PxylX promoter (Figure 1). This marker is referred to throughout the text as xylbla.

To replace $x y l X$ by blaA, we constructed plasmid pxylblaE2, containing blaA flanked by $5^{\prime}$ and $3^{\prime}$ homology regions surrounding $x y l X$, as follows. First, blaA and blaB primers were used for the amplification of blaA flanked by EcoRI and BamHI restriction sites. A region of homology immediately $3{ }^{\circ}$ of $x y l X$ was amplified using primers xylC
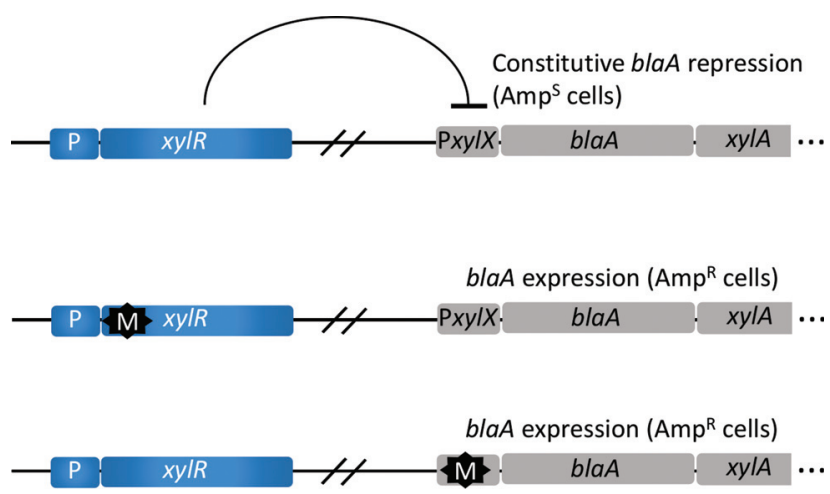

Figure 1 - Rationale of the $x y l b l a$ marker. The $x y l X$ gene in the $x y l$ operon has been replaced by blaA. Nevertheless, repression by XylR in the absence of xylose renders cells phenotypically Amps. Cells can become phenotypically $\mathrm{Amp}^{\mathrm{R}}$ by loss of function mutations (M) in $x y l R$, or by mutations in the $x y l R$ operator inside PxylX. and xylD, which introduced BamHI and SpeI restriction sites 5 and $3{ }^{\prime}$ respectively. A large fragment containing the whole $x y l X$ gene and flanking regions was obtained with primers xylA (introducing a HindIII site in the 5 portion) and xylD. This amplicon possesses a natural EcoRI site. Digestion of this fragment with HindIII and EcoRI produced a shorter fragment of $636 \mathrm{bp}$, corresponding to the region immediately 5 to $x y l X$ plus the first $18 \mathrm{bp}$ of the open reading frame. Ligation of the three fragments in $\mathrm{pBC} \mathrm{KS}+$ yielded a construct containing blaA flanked by regions of homo$\operatorname{logy}$ to the $5^{\prime}$ and $3^{\circ}$ of $x y l X$. This fragment was subcloned in pNPTS138 to produce the pNPTxylblaE2 construct.

The first recombination event, integrating pNPTxylblaE2 into the $C$. crescentus chromosome, was obtained by conjugation of $C$. crescentus CS606 ( $\triangle$ blaA $)$ with $E$. coli S17.1 carrying pNPTxylblaE2, selecting for $\mathrm{Kan}^{\mathrm{R}} \mathrm{Nal}^{\mathrm{R}}$ conjugants. Afterwards, a second recombination event, leading to plasmid loss, was selected by plating cells in PYE medium supplemented with 3\% sucrose. The resulting clones were screened for xylose auxotrophy, to look for strains with the substitution of $x y l X$ by blaA. As expected, these recombinants yielded spontaneous $A m p^{R}$ mutants, unlike the parental strain CS606. One of these recombinants, designated RSG113, was chosen for the experiments. $\operatorname{din} B$ and imuC derivatives of RSG113 were constructed using $\Phi \mathrm{Cr} 30$ transduction, using GM40 and GM50 strains as donors.

\section{Fluctuation tests and determination of mutation sequences}

Fluctuation tests for measurement of mutation rates were initiated by diluting a saturated culture to $\sim 10^{2}$ cells $/ \mathrm{mL}$ in PYE medium. This diluted culture was split in 11 tubes containing $1 \mathrm{~mL}$ of cell suspension each, which were grown for $48 \mathrm{~h}$ at $30^{\circ} \mathrm{C}$. Cell viability was determined by serial dilution and plating on PYE. The number of mutants was determined as follows for each of the markers used for mutagenesis studies. Due to the high frequency of mutants, in the assays using the xylbla and cItet markers, $100 \mu \mathrm{L}$ of each culture was plated in duplicate in PYE Amp and PYE Tet respectively. Mutation rates were calculated by the Ma-Sandri-Sarkar Maximum Likelihood Estimator (MSS-MLE) using the FluCalc web tool (Radchenko et al., 2018).

All the $\mathrm{Tet}^{\mathrm{R}}$ and $\mathrm{Amp}^{\mathrm{R}}$ mutants sequenced for the determination of the mutational spectrum come from independent cultures in the fluctuation assays, to ensure independent mutations were assessed. Mutations were detected and analyzed for sequence quality using the Genious R8 software (Biomatters).

To determine the sequences of the $\operatorname{Tet}^{\mathrm{R}}$ mutations, the cI gene was amplified using primers cItetfwd and cItetrev. Purified PCR products were sequenced using primers cIfwd, cIrev, cItet-Seq and cItet-int. 
Since two classes of mutants are detectable in the xylbla assay, we first identified the two classes of mutants using a previously reported inability of $x y l R$ mutants to grow on minimal medium containing glucose as a carbon source. Therefore, $A m p^{R}$ colonies were first spotted on PYE and M2 glucose media. Mutants unable to grow on minimal media were sequenced for mutations in $x y l R$, and the remainder were sequenced for mutations on PxylX. To sequence $x y l R$, a PCR product was obtained with primers xylR-fwd and xylR-rev, and subsequently sequenced with the same primers and xylR-seq-final, xylR-seq-1. Mutations in PxylX were determined by PCR with primers Pxylx-fwd and blaB, and sequenced with Pxylx-fwd and PxylX-seq.

\section{Results}

\section{Forward mutational assays in $C$. crescentus}

In order to have better experimental tools for the study of mutagenesis in C. crescentus, we constructed two sets of strains (parental, and its $\operatorname{din} B$ and $i m u C$ derivatives) containing different forward mutational assays. The first set contains the cItet marker, previously developed for mutagenesis studies in E. coli (Bjedov et al., 2007). The other contains a newly developed marker, xylbla (Figure 1). It uses the well-known xylose inducible $x y l X$ promoter, which is controlled by the LacI family repressor XylR (Meisenzahl et al., 1997; Stephens et al., 2007b). In this system, the bla gene encoding a beta-lactamase naturally present in $C$. crescentus was put under control of PxylX, rendering cells phenotypically Amp ${ }^{\mathrm{S}}$. Two types of mutations are conceivable in this system. Mutations that disrupt the operator sequence in PxylX, and mutations that inactivate the XylR repressor, as depicted in Figure 1. $x y l R$ and PxylX mutants can be distinguished based on the poor growth of the former on minimal media containing glucose as the sole carbon source, as reported before (Stephens et al., 2007b). C. crescentus cells carrying cItet give rise to spontaneous $\mathrm{Tet}^{\mathrm{R}}$ mutants, and those carrying the xylbla marker give rise to spontaneous $\mathrm{Amp}^{\mathrm{R}}$ mutants, unlike the NA1000 strain. Sequencing revealed that both $\mathrm{Amp}^{\mathrm{R}}$ and $\mathrm{Tet}^{\mathrm{R}}$ mutants carry mutations in the predicted targets (see below). Therefore, we successfully used forward mutational assays for this model organism.

\section{Roles of $\operatorname{din} B$ and imuC in spontaneous mutagenesis}

We sought to determine the role of $\operatorname{din} B$ and $i m u C$ in spontaneous mutagenesis using both markers in fluctuation assays (Figure 2). The results show that both the $\operatorname{din} B$ and imuC strains show $\mathrm{Amp}^{\mathrm{R}}$ and $\mathrm{Tet}^{\mathrm{R}}$ mutation rates comparable to the respective parental strains. In the case of $i m u C$, mutation rates are indistinguishable from the parental strains ones in both markers, given the overlap in the confidence intervals. The $\operatorname{din} B$ strain shows comparable Amp ${ }^{\mathrm{R}}$

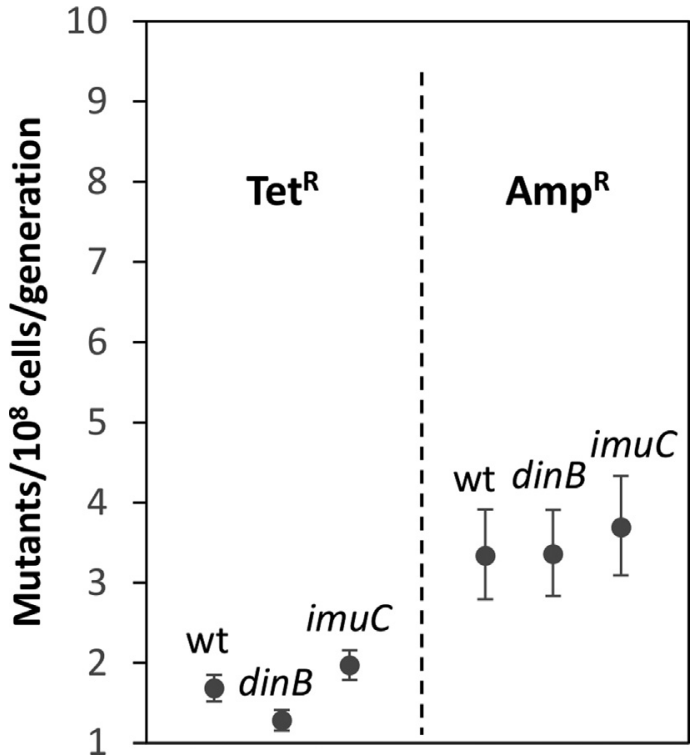

Figure 2 - $\operatorname{Tet}^{\mathrm{R}}$ and $A m p^{\mathrm{R}}$ mutation rates. Tet ${ }^{\mathrm{R}}$ mutation rates were determined using 66 cultures from 6 independent experiments. Amp ${ }^{\mathrm{R}}$ mutation rates were determined using 55 cultures from 5 independent experiments. Both the parental strains containing the cItet and xylbla markers (wt) and their $\operatorname{din} B$ and imu $C$ derivatives were analyzed. Mutation rates and $95 \%$ confidence intervals (represented by the error bars) were calculated using the MSS-MLE (Ma-Sandri-Sarkar Maximum Likelihood Estimator).

mutation rates, but slightly decreased $\mathrm{Tet}^{\mathrm{R}}$ mutagenesis. Nevertheless, the small difference observed (less than 2fold) is usually not considered biologically relevant. These results confirm our previous observations using the more limited $r р о B$ marker, which can only detect base substitutions. In those experiments, we showed that imu $C$ does not influence the rate of Rif $^{\mathrm{R}}$ mutations (Martins-Pinheiro et al., 2017). Although these results indicate that both DinB and ImuABC have a limited role in spontaneous mutagenesis, we reasoned that quantitative determination of mutation rates lack the sensitivity to detect small, but biologically important, changes in the mutational signatures in cells lacking these polymerases, as exemplified by the small differences in $\mathrm{Tet}^{\mathrm{R}}$ mutants observed in the $\operatorname{din} B$ strain. Therefore, we proceeded to analyze the sequences of spontaneous mutations found in all loci under study.

\section{Spontaneous mutation signatures in $\mathrm{Cl}$}

We analyzed the sequences of $\mathrm{Tet}^{\mathrm{R}}$ mutants obtained with the set of strains containing the cItet marker, and the results are represented in Figure 3. The positions of all mutations analyzed are described in Table S2. In all strains, small indels account for a large fraction of the mutations observed, in agreement with studies in other organisms using similar markers (Schaaper et al., 1986). All these mutations are localized in homopolymeric runs in $c I$ (data not shown). Both $\operatorname{din} B$ and imuC strains show alterations in the number of such frameshifts. 1 bp deletions represent $30 \%$ of the mutations observed in the parental strain, and approximately $15 \%$ of the mutations observed in the $i m u C$ de- 


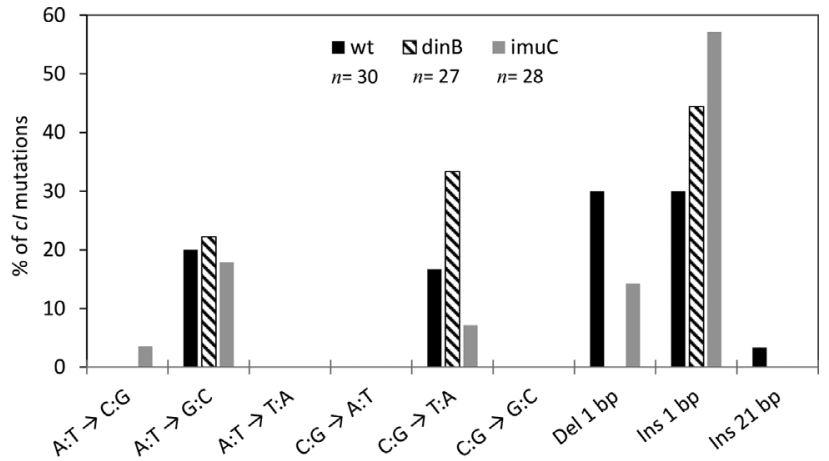

Figure 3 - Distribution of the different base substitutions in $c I$ in wt, $\operatorname{din} B$ and $i m u C$ strains. Results are shown for NA1000 strain (wt) and mutant strains $(\operatorname{din} B$ and $i m u C) . n$ indicates the number of mutants analyzed in each strain. The different base substitutions are indicated. Del $1 \mathrm{bp}: 1 \mathrm{bp}$ deletions. Ins 1 bp: 1 bp insertions. Ins 21 bp: 21 bp insertion detected in the wt strain.

rivative. No -1 frameshifts were detected in the $\operatorname{din} B$ strain among the $\mathrm{Tet}^{\mathrm{R}}$ mutants analyzed. On the other hand, both $\operatorname{din} B$ and $i m u C$ deficiencies lead to an increase in the number of $1 \mathrm{bp}$ insertions in $\mathrm{cI}$.

Previously, we have described that the spontaneous base substitution signature of $C$. crescentus in the rpoB gene is dominated by $\mathrm{A}: \mathrm{T} \rightarrow \mathrm{G}: \mathrm{C}$ transitions, which is different from the bias towards $\mathrm{C}: \mathrm{G} \rightarrow \mathrm{T}$ :A observed in most organisms studied to date (Martins-Pinheiro et al., 2017). The sequences of mutations in $c I$ confirm this trend, given that $\mathrm{A}: \mathrm{T} \rightarrow \mathrm{G}: \mathrm{C}$ changes outnumber $\mathrm{C}: \mathrm{G} \rightarrow \mathrm{T}: \mathrm{A}$ transitions in the wt background. Curiously, the number of $\mathrm{C}: \mathrm{G} \rightarrow \mathrm{T}: \mathrm{A}$ substitutions is increased in the $\operatorname{din} B$ background, but decreased in $i m u C$.

\section{Spontaneous mutation signatures in $x y I R$}

The spectrum of spontaneous mutations in $x y l R$ is summarized in Figure 4. The positions of all mutations analyzed are described in Table S3. This gene has a very pronounced mutational hotspot, in which a cytosine insertion occurs after base 230 of the open reading frame (Figure S1). Interestingly, this hotspot does not consist of a homopolymeric run, and does not present any obvious secondary structure formation. Therefore, the basis for the presence of this hotspot is not known. The $\operatorname{din} B$ strain shows a marked increase in the proportion of mutations in this hotspot.

Apart from mutations in the hotspot, the $\operatorname{din} B$ strain lacks 1 bp deletions in homopolymeric runs in $x y l R$, as seen in $c I$, suggesting that those are, to a large extent, generated by Pol IV activity in C. crescentus. Another feature in common between the two markers is that $\mathrm{A}: \mathrm{T} \rightarrow \mathrm{G}: \mathrm{C}$ transitions are the most frequent type of base substitution observed in the wt strain. The same is observed for $\operatorname{din} B$ and $i m u C$ mutants in $x y l R$. Both $\operatorname{din} B$ and imu $C$ deficiency cause an increase in the number of $\mathrm{C}: \mathrm{G} \rightarrow \mathrm{T}:$ A mutations in $x y l R$, a feature not observed in the $c I$ gene for the imuC mutant, in which we observed the opposite effect. Neverthe-

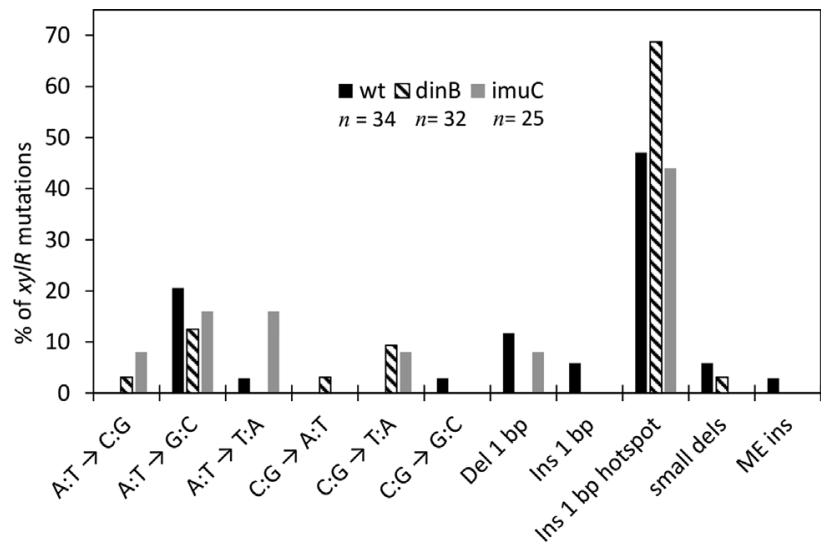

Figure 4 - Distribution of the different base substitutions in $x y l R$ in wt, $\operatorname{din} B$ and $i m u C$ strains. The different base substitutions are indicated. Del 1 bp: 1 bp deletions. Ins 1 bp: 1 bp insertions not located in the hotspot. Ins 1 bp hotspot: 1 bp insertions located in the hotspot. Small dels: 2-8 bp deletions. ME ins: insertion of mobile elements. $n$ indicates the number of mutants analyzed in each strain.

less, $\operatorname{din} \mathrm{B}$ deficiency leads to an increase of $\mathrm{C}: \mathrm{G} \rightarrow \mathrm{T}: \mathrm{A}$ in both markers. Other differences in the patterns of base substitutions in $x y l R$ can be seen among the strain backgrounds, with the $i m u C$ strain showing more $\mathrm{A}: \mathrm{T} \rightarrow \mathrm{T}: \mathrm{A}$ and $\mathrm{A}: \mathrm{T} \rightarrow \mathrm{C}: \mathrm{G}$ transversions. Taken together, the results obtained with the two loci point to a clear role of $\operatorname{din} B$ in preventing $1 \mathrm{bp}$ insertions and $\mathrm{C}: \mathrm{G} \rightarrow \mathrm{T}: \mathrm{A}$ transitions, and in the formation of $-1 \mathrm{bp}$ frameshifts. Minor changes in the mutational spectrum can be seen in the imuC strain. This polymerase seems to have a role in preventing $\mathrm{A}: \mathrm{T} \rightarrow \mathrm{T}: \mathrm{A}$ mutations in $x y l R$ and $\mathrm{A}: \mathrm{T} \rightarrow \mathrm{C}: \mathrm{G}$ transversions in both markers.

\section{Spontaneous mutation signatures in $\mathrm{P} x y I X$}

We also investigated the $\mathrm{Amp}^{\mathrm{R}}$ mutations localized in PxylX in cells carrying the xylbla marker. Although the 14 bp operator sequence is a very small mutational target compared to the $1.25 \mathrm{kp}$ long $x y l R$ ORF, we observed that P $x y l X$ mutations correspond to approximately $1 / 4$ of all $\mathrm{Amp}^{\mathrm{R}}$ mutations in cells carrying xylbla (data not shown). There is no significant variation among the three strain backgrounds, but there is a remarkable reversion of the mutational bias observed in rpoB (Martins-Pinheiro et al., 2017), $c I$ and $x y l R$ (Figure 5A). Here, we find that $\mathrm{C}: \mathrm{G} \rightarrow$ $\mathrm{T}: \mathrm{A}$ mutations largely outnumber $\mathrm{A}: \mathrm{T} \rightarrow \mathrm{G}: \mathrm{C}$ transitions. $\mathrm{C}: \mathrm{G} \rightarrow \mathrm{T}: \mathrm{A}$ mutations are detected in 3 independent positions within the XylR operator located in PxylX, ruling out a hotspot to account for the results (Figure 5B). Another striking point is that no frameshifts were observed among all the PxylX mutations analyzed.

\section{Discussion}

In this work, we have successfully implemented two forward markers for mutagenesis studies in C. crescentus. 


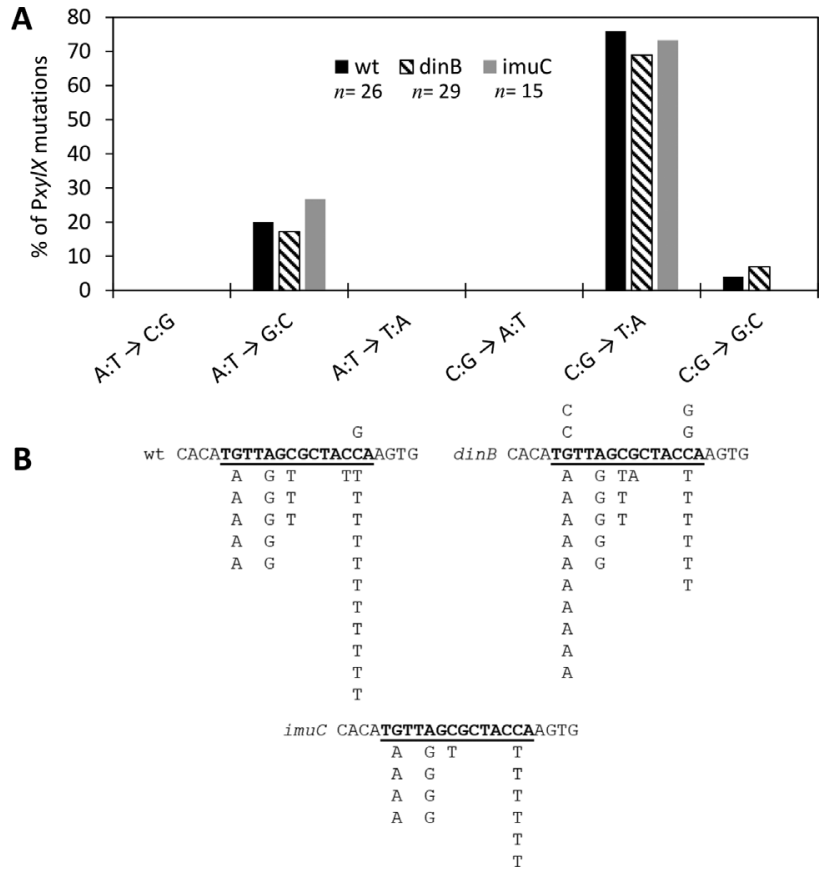

Figure 5 - P $x y l X$ mutations. (A) Distribution of the different base substitutions in PxylX in wt (parental strain), $\operatorname{din} B$ and $i m u C$ strains. The different base substitutions are indicated. $n$ indicates the number of mutants analyzed in each strain. (B) A small region in the PxylX region is shown, with the XylR binding site underlined. Sequences above and below the line show the different mutations detected.

Using these tools, we confirmed previous observations in which a $\mathrm{A}: \mathrm{T} \rightarrow \mathrm{G}: \mathrm{C}$ mutations are the most prevalent type of base substitution observed in C. crescentus (MartinsPinheiro et al., 2017). Curiously, this is the predominant type of mutation found in mismatch repair deficient $E$. coli, but not wild type cells (Lee et al., 2012). In wild type $E$. coli, as well as in many other organisms, $\mathrm{C}: \mathrm{G} \rightarrow \mathrm{A}: \mathrm{T}$ mutations predominate (Lee et al., 2012), and have been proposed as the universal mutational bias in bacteria (Hershberg and Petrov, 2010; Hildebrand et al., 2010). These forward mutational markers will be valuable tools for future studies aiming at understanding such difference between $C$. crescentus and most other organisms.

Nevertheless, we spotted an interesting deviation of this $\mathrm{A}: \mathrm{T} \rightarrow \mathrm{G}: \mathrm{C}$ bias in $C$. crescentus. When mutations in the $\mathrm{P} x y l X$ region werere analyzed, there was a clear shift in the predominant mutation type, with $\mathrm{C}: \mathrm{G} \rightarrow \mathrm{T}: \mathrm{A}$ transitions being the most frequent base substitution. The basis for this deviation is not yet understood. We envision two not mutually exclusive explanations. First, it is possible that lesions giving rise to $\mathrm{C}: \mathrm{G} \rightarrow \mathrm{T}: \mathrm{A}$ transitions, such as uracil residues formed by spontaneous cytosine deamination, are repaired more efficiently in transcribed regions compared to non-transcribed ones. Second, the constant binding of the XylR repressor to the operator sequence could hinder the access of repair proteins to DNA lesions and/or affect the rate of lesion formation. These two hy- potheses could also help to explain the proportionally higher mutation rates in the small Pxyl $X$ target.

We also analyzed the role of the error-prone DNA polymerases ImuC and DinB in spontaneous mutagenesis. imuC is controlled by the SOS response in C. crescentus, whereas $\operatorname{din} B$ is not (Galhardo et al., 2005; da Rocha et al., 2008). Additionally, no conditions where $\operatorname{din} B$ expression is increased has been found in high throughput studies under DNA damaging conditions (Modell et al., 2011). Therefore, to the best of our knowledge, $\operatorname{din} B$ expression is constitutive in $C$. crescentus, unlike in other bacteria, such as E. coli and Pseudomonas aeruginosa (Courcelle et al., 2001; Sanders et al., 2006), but similar to M. tuberculosis, where the two $\operatorname{din} B$ orthologs are not part of the SOS regulon (Kana et al., 2010; Smollett et al., 2012). This observation is reminiscent of the data in C. crescentus and indicates that inducibility by DNA damage is not a universal feature of $\operatorname{din} B$ in bacteria. Furthermore, the M. tuberculosis orthologs have no obvious role in DNA damage tolerance, and do not influence the rate and spectrum of spontaneous mutagenesis (Kana et al., 2010).

In C. crescentus we found that this polymerase plays a role in spontaneous mutagenesis, given that $1 \mathrm{bp}$ deletions seem to be totally DinB-dependent. Interestingly, ImuC also plays a role in the genesis of this same type of mutation. These mutations typically arise in homopolymeric runs, as a consequence of replication slippage. DinB overexpression has been long known to lead to an increase in the number of 1bp deletions (Kim et al., 1997, 2001), which occur through a dNTP-stabilized misalignment (Kobayashi et al., 2002). Nevertheless, our data suggest that physiological levels of DinB promote such mutagenesis in C. crescentus. Future studies are needed to understand if this phenomenon happens during TLS of endogenous lesions, or simply by gaining access to ongoing replication of undamaged templates. Another possibility is that DinB may be mutagenic in DNA synthesis during recombination intermediates (Pomerantz et al., 2013). Stress-induced mutagenesis in non-growing cells also has a strong $\operatorname{din} B$-dependence (Mckenzie et al., 2001). It could be the case that upon saturation of the cultures and cessation of growth, a $\operatorname{din} B$-dependent stress-induced mechanism is triggered in C. crescentus, contributing to the appearance of the DinBdependent frameshifts in the fluctuation assays. Nevertheless, cultures were plated only a few hours after they reached saturation in our experimental conditions, and not after the longer periods of time required to detect stressinduced mutations (Shee et al., 2011).

Also, in both $c I$ and $x y l R$ the absence of $\operatorname{din} B$ leads to an increase in the proportion of $C: G \rightarrow T: A$ transitions. This may indicate a role of this constitutively expressed polymerase in maintaining the $\mathrm{A}: \mathrm{T} \rightarrow \mathrm{C}: \mathrm{G}$ bias in $C$. crescentus. Other types of mutations were found to be influenced by error-prone polymerases, such as the $\mathrm{A}: \mathrm{T} \rightarrow \mathrm{C}: \mathrm{G}$ and $\mathrm{A}: \mathrm{T} \rightarrow$ $\mathrm{T}: \mathrm{A}$ transversions in $x y l R$, both increased in the imuC back- 
ground. In $c I$, ImuC seems to contribute to the formation of $\mathrm{C}: \mathrm{G} \rightarrow \mathrm{T}: \mathrm{A}$ transitions. The loci specificity of these observations probably reflects local sequence contexts that may either favor increased endogenous lesion formation, or hinder DNA repair, providing lesion substrates for translesion synthesis by these polymerases. This is evident in the case of $x y l R$ mutations in the $i m u C$ strain, where some of the A:T $\rightarrow \mathrm{T}$ :A events occurred in the same position (Table S3).

Altogether, our results point to a role of DinB in the genesis of small deletions in C. crescentus cells not exposed to DNA-damaging agents. This study also demonstrates the importance of detailed analysis of mutational spectra, showing that it can reveal important small-scale changes in the proportion of base substitutions across different genetic backgrounds, which cannot be assessed by mere quantification of mutation rates.

\section{Acknowledgments}

The authors would like to thank Ivan Matic and Craig Stephens for the kind gifts of bacterial strains. V.S.B. and M.M. were recipients of FAPESP fellowships (2011/09465-0 and 2010/20780-2). This study was financed in part by the Coordenação de Aperfeiçoamento de Pessoal de Nível Superior - Brasil (CAPES) - Finance Code 001, and by grants 2009/51387-7 and 2014/15982-6 from FAPESP.

\section{Conflict of Interest}

None to declare.

\section{Author Contributions}

RSG conceived the study, AOV, MM and VSB performed the experiments, RSG wrote the paper.

\section{References}

Alves IR, Lima-Noronha MA, Silva LG, Fernández-Silva FS, Freitas ALD, Marques MV and Galhardo RS (2017) Effect of SOS-induced levels of imuABC on spontaneous and damage-induced mutagenesis in Caulobacter crescentus. DNA Repair (Amst) 59:20-26.

Bagg A, Kenyon CJ and Walker GC (1981) Inducibility of a gene product required for UV and chemical mutagenesis in Escherichia coli. Proc Natl Acad Sci U S A 78:5749-5753.

Bjedov I, Dasgupta CN, Slade D, Le Blastier S, Selva M and Matic I (2007) Involvement of Escherichia coli DNA polymerase IV in tolerance of cytotoxic alkylating DNA lesions in vivo. Genetics 176:1431-1440.

Boshoff HIM, Reed MB, Barry III CE and Mizrahi V (2003) DnaE2 polymerase contributes to in vivo survival and the emergence of drug resistance in Mycobacterium tuberculosis. Cell 113:183-193.

Caillet-Fauquet P and Maenhaut-Michel G (1988) Nature of the SOS mutator activity: Genetic characterization of untargeted mutagenesis in Escherichia coli. Mol Gen Genet 213:491-498.
Cirz RT, Chin JK, Andes DR, de Crécy-Lagard V, Craig WA and Romesberg FE (2005) Inhibition of mutation and combating the evolution of antibiotic resistance. PLoS Biol 3:e176.

Courcelle J, Khodursky A, Peter B, Brown PO and Hanawalt PC (2001) Comparative gene expression profiles following UV exposure in wild-type and SOS-deficient Escherichia coli. Genetics 158:41-64.

da Rocha RP, Paquola AC, Marques MV, Menck CF and Galhardo RS (2008) Characterization of the SOS regulon of Caulobacter crescentus. J Bacteriol 190:1209-1218.

Drake J (1991) A constant rate of spontaneous mutation in DNAbased microbes. Proc Natl Acad Sci U S A 88:7160-7164.

Ely B (1991) Genetics of Caulobacter crescentus. Methods Enzymol 204:372-384.

Fuchs RP and Fujii S (2013) Translesion DNA synthesis and mutagenesis in prokaryotes. Cold Spring Harb Perspect Biol 5:a012682.

Galhardo RS, Rocha RP, Marques MV and Menck CFM (2005) An SOS-regulated operon involved in damage-inducible mutagenesis in Caulobacter crescentus. Nucleic Acids Res 33:2603-2614.

Galhardo RS, Hastings PJ and Rosenberg SM (2007) Mutation as a stress response and the regulation of evolvability. Crit Rev Biochem Mol Biol 42:399-435.

Goodman MF, McDonald JP, Jaszczur MM and Woodgate R (2016) Insights into the complex levels of regulation imposed on Escherichia coli DNA polymerase V. DNA Repair (Amst) 44:42-50.

Hershberg R and Petrov DA (2010) Evidence that mutation is universally biased towards AT in bacteria. PLoS Genet 6:e1001115.

Hildebrand F, Meyer A and Eyre-Walker A (2010) Evidence of selection upon genomic GC-content in bacteria. PLoS Genet 6:e1001107.

Jarosz DF, Godoy VG, Delaney JC, Essigmann JM and Walker GC (2006) A single amino acid governs enhanced activity of DinB DNA polymerases on damaged templates. Nature 439:225-228.

Kana BD, Abrahams GL, Sung N, Warner DF, Gordhan BG, Machowski EE, Tsenova L, Sacchettini JC, Stoker NG, Kaplan G et al. (2010) Role of the DinB homologs Rv1537 and Rv3056 in Mycobacterium tuberculosis. J Bacteriol 192:2220-2227.

Kato T and Shinoura Y (1977) Isolation and characterization of mutants of Escherichia coli deficient in induction of mutations by ultraviolet light. Mol Gen Genet 156:121-131.

Kenyon CJ and Walker GC (1980) DNA-damaging agents stimulate gene expression at specific loci in Escherichia coli. Proc Natl Acad Sci U S A 77:2819-2823.

Kim SR, Maenhaut-Michel G, Yamada M, Yamamoto Y, Matsui K, Sofuni T, Nohmi T and Ohmori H (1997) Multiple pathways for SOS-induced mutagenesis in Escherichia coli: An overexpression of $\operatorname{din} \mathrm{B} / \mathrm{din} \mathrm{P}$ results in strongly enhancing mutagenesis in the absence of any exogenous treatment to damage DNA. Proc Natl Acad Sci U S A 94:13792-13797.

Kim SR, Matsui K, Yamada M, Gruz P and Nohmi T (2001) Roles of chromosomal and episomal dinB genes encoding DNA pol IV in targeted and untargeted mutagenesis in Escherichia coli. Mol Genet Genomics 266:207-215.

Kobayashi S, Valentine MR, Pham P, O'Donnell M and Goodman MF (2002) Fidelity of Escherichia coli DNA polymer- 
ase IV. Preferential generation of small deletion mutations by dNTP-stabilized misalignment. J Biol Chem 277:34198-34207.

Kuban W, Jonczyk P, Gawel D, Malanowska K, Schaaper RM and Fijalkowska IJ (2004) Role of Escherichia coli DNA polymerase IV in in vivo replication fidelity. J Bacteriol 186:4802-4807.

Layton JC and Foster PL (2003) Error-prone DNA polymerase IV is controlled by the stress-response sigma factor, RpoS, in Escherichia coli. Mol Microbiol 50:549-561.

Lee H, Popodi E, Tang H and Foster PL (2012) Rate and molecular spectrum of spontaneous mutations in the bacterium Escherichia coli as determined by whole-genome sequencing. Proc Natl Acad Sci U S A 109:E2774-E2783.

Lynch M (2010) Evolution of the mutation rate. Trends Genet 26:345-352.

Martins-Pinheiro M, Oliveira AR, Valencia AO, Fernandez-Silva FS, Silva LG, Lopes-Kulishev CO, Italiani VCS, Marques MV, Menck CF and Galhardo RS (2017) Molecular characterization of Caulobacter crescentus mutator strains. Gene 626:251-257.

Mckenzie GJ, Lee PL, Lombardo M, Hastings PJ and Rosenberg SM (2001) SOS mutator DNA polymerase IV functions in adaptive mutation and not adaptive amplification. Mol Cell 7:571-579.

McKenzie GJ, Magner DB, Lee PL and Rosenberg SM (2003) The $\operatorname{din} B$ operon and spontaneous mutation in Escherichia coli. J Bacteriol 185:3972-3977.

Meisenzahl AC, Shapiro L and Jenal U (1997) Isolation and characterization of a xylose-dependent promoter from Caulobacter crescentus. J Bacteriol 179:592-600.

Modell JW, Hopkins AC and Laub MT (2011) A DNA damage checkpoint in Caulobacter crescentus inhibits cell division through a direct interaction with FtsW. Genes Dev 25:1328-1343.

Ohmori H, Friedberg EC, Fuchs RPP, Goodman MF, Hanaoka F, Hinkle D, Kunkel TA, Lawrence CW, Livneh Z, Nohmi T et al. (2001) The Y-family of DNA polymerases. Mol Cell $8: 7-8$.

Pérez-Capilla T, Baquero MR, Gómez-Gómez JM, Ionel A, Martín S and Blázquez J (2005) SOS-independent induction of $\operatorname{din} B$ transcription by $\beta$-lactam-mediated inhibition of cell wall synthesis in Escherichia coli. J Bacteriol 187:1515-1518.

Petrosino JF, Galhardo RS, Morales LD and Rosenberg SM (2009) Stress-induced beta-lactam antibiotic-resistance mutation and the sequences of stationary-phase mutations in the Escherichia coli chromosome. J Bacteriol 191:5881-5889.

Pomerantz RT, Goodman MF and O'Donnell ME (2013) DNA polymerases are error-prone at RecA-mediated recombination intermediates. Cell Cycle 12:2558-2563.

Radchenko EA, McGinty RJ, Aksenova AY, Neil AJ and Mirkin SM (2018) Quantitative analysis of the rates for repeatmediated genome instability in a yeast experimental system. Methods Mol Biol 1672:421-438.
Sanders LH, Rockel A, Lu H, Wozniak DJ and Sutton MD (2006) Role of Pseudomonas aeruginosa dinB-encoded DNA polymerase IV in mutagenesis. J Bacteriol 188:8573-8585.

Schaaper RM, Danforth BN and Glickman BW (1986) Mechanisms of spontaneous mutagenesis: an analysis of the spectrum of spontaneous mutation in the Escherichia coli lacI gene. J Mol Biol 189:273-284.

Shee C, Gibson JL, Darrow MC, Gonzalez C and Rosenberg SM (2011) Impact of a stress-inducible switch to mutagenic repair of DNA breaks on mutation in Escherichia coli. Proc Natl Acad Sci U S A 108:13659-13664.

Smollett KL, Smith KM, Kahramanoglou C, Arnvig KB, Buxton RS and Davis EO (2012) Global analysis of the regulon of the transcriptional repressor LexA, a key component of SOS response in Mycobacterium tuberculosis. J Biol Chem 287:22004-22014.

Stephens C, Christen B, Fuchs T, Sundaram V, Watanabe K and Jenal U (2007a) Genetic analysis of a novel pathway for D-xylose metabolism in Caulobacter crescentus. J Bacteriol 189:2181-2185.

Stephens C, Christen B, Watanabe K, Fuchs T and Jenal U (2007b) Regulation of D-xylose metabolism in Caulobacter crescentus by a LacI-type repressor. J Bacteriol 189:8828-8834.

Warner DF, Ndwandwe DE, Abrahams GL, Kana BD, Machowski EE, Venclovas C, Mizrahi V and Benkovic SJ (2010) Essential roles for imuA'- and imuB-encoded accessory factors in DnaE2-dependent mutagenesis in Mycobacterium tuberculosis. Proc Natl Acad Sci U S A 107:13093-13098.

West L, Yang D and Stephens C (2002) Use of the Caulobacter crescentus genome sequence to develop a method for systematic genetic mapping. J Bacteriol 184:2155-2166.

Wolff E, Kim M, Hu K, Yang H and Miller JH (2004) Polymerases leave fingerprints: analysis of the mutational spectrum in Escherichia coli rpoB to assess the role of polymerase IV in spontaneous mutation. J Bacteriol 186:2900-2905.

Woodgate R (1992) Construction of a umuDC operon substitution mutation in Escherichia coli. Mutat Res 281:221-225.

\section{Internet Resources}

FluCalc, http://flucalc.ase.tufts.edu.

\section{Supplementary material}

The following online material is available for this article:

Figure S1 - Mutational hotspot in the $x y l R$ gene.

Table S1 - Primers used in this study.

Table S2 - Location of the mutations in the $c I$ gene.

Table S3 - Location of the mutations in the $x y l R$ gene.

Associate Editor: Catarina S. Takahashi

License information: This is an open-access article distributed under the terms of the Creative Commons Attribution License (type CC-BY), which permits unrestricted use, distribution and reproduction in any medium, provided the original article is properly cited. 